\title{
Prediction of canola and spring wheat yield based on the Canadian Meteorological Centre's monthly forecasting system
}

\author{
A. C. Chipanshi ${ }^{1, *}$, D. Qi ${ }^{1}$, Y. Zhang ${ }^{2}$, H. Lin ${ }^{3}$, N. K. Newlands ${ }^{4}$ \\ ${ }^{1}$ Science and Technology Branch, Agriculture and Agri-Food Canada, 300-2010-12th Avenue, Regina, Saskatchewan S4P 0M3, \\ Canada \\ ${ }^{2}$ Science and Technology Branch, Agriculture and Agri-Food Canada, 960 Carling Avenue, Ottawa, Ontario K1A 0C6, Canada \\ ${ }^{3}$ Canadian Meteorological Centre, Environment and Climate Change Canada, 2121 route Transcanadienne, Dorval, Quebec \\ H9P 1J3, Canada \\ ${ }^{4}$ Science and Technology Branch, Agriculture and Agri-Food Canada, 4200 Highway 97, Summerland, British Columbia \\ V0H 1Z0, Canada
}

\begin{abstract}
With the goal of popularizing the use of readily available data sets from numerical weather prediction models in crop yield forecasting, we present a comparative analysis of end of season forecasts of wheat and canola from daily values of maximum and minimum temperature and total daily precipitation across the Canadian Prairies from (1) the Global Ensemble Prediction System (GEPS) and (2) statistically generated values from climate stations. The analysis was done using the Canadian Crop Yield Forecaster (CCYF), a tool for conducting crop yield outlooks within the growing season. We found that the GEPS data sets provided skillful forecasts of spring wheat and canola from selected Census of Agricultural Regions (CARs) in Alberta, Manitoba and Saskatchewan. Aggregated results for the Prairie region showed that the GEPS data had a similar predictive skill as the statistically generated values of temperature and precipitation for spring wheat and showed improved prediction skill overall for canola from the provinces of Alberta and Saskatchewan. In the Canadian Prairie environment, where climatic records are short and spatially insufficient, the GEPS data set, which is produced every Thursday and gridded at $45 \mathrm{~km}$ resolution, can be used as a substitute for, or supplement to, station-generated climate variables. Because of the continuous improvement in numerical prediction models such as GEPS in terms of skill score and resolution, the testing of crop forecasting models should be done at regular intervals to take advantage of these data sets as they become available.
\end{abstract}

KEY WORDS: Canadian Crop Yield Forecaster - CCYF - Canola · Spring wheat - Global Environmental Prediction System • Normalized Difference Vegetation Index

\section{INTRODUCTION}

In an attempt to contribute to a food-secure world, several national or state-sponsored agencies provide crop forecasting information which is used to inform policy, commodity brokers, transporters and emergency responders in a timely manner. Examples of agencies that routinely provide crop forecast information include the European Commission Joint Re-

${ }^{*}$ Corresponding author: aston.chipanshi@canada.ca search Centre (JRC) for European countries (van Diepen et al. 2004), China Crop Watch for China and the world (Wu et al. 2014), the Queensland Alliance for Agriculture and Food Innovation (QAAFI) and the Department of Agriculture and Food of Western Australia (DAFWA) for Australia (Nikolova et al. 2012), the National Agricultural Statistics Service (NASS) of the United States Department of Agriculture (USDA) for the United States of America (Johnson 2014) and

(C) The authors 2019. Open Access under Creative Commons by Attribution Licence. Use, distribution and reproduction are unrestricted. Authors and original publication must be credited. 
Statistics Canada for Canada (Reichert \& Caissy 2002). Using these regional outlook assessments of crop yield, other groups such as the United States Agency for International Development (USAID), Food and agriculture Organization (FAO) and aid organizations amalgamate this information (including noncrop yield data such as crop prices and stock numbers) to produce global maps of food insecurity for early warning purposes (FAO 2014, USAID 2014).

The tools for making crop yield forecasts and projections range from statistical to biophysical models. Statistical models are based on crop production relationships, whereby crop yield projections are expressed as functions of some defined variables with regression coefficients obtained from linear or nonlinear relationships (Walker 1989, Stephens et al. 1994, Qian et al. 2009). Although statistical models are useful for comparing means and outcomes from multiple experiments, their application is limited because of the need to calibrate these models locally (Jame \& Cutforth 1996). Biophysical models integrate knowledge from other disciplines such as agrometeorology, crop and soil sciences using a systems approach framework to describe how various processes affect plant growth and development (Hoogenboom et al. 2017). While integration is a powerful attribute for the purposes of understanding the factors that bring about variations in predicted yields, biophysical models require detailed data inputs at the soil, plant and atmospheric levels. Usually such data sets are available only at selected experimental sites, and therefore, biophysical models are difficult to use over extensive areas in an operational mode. In order to find a practical model that can be used in near real-time for forecasting crop yields, functional models have been developed by incorporating elements of both statistical and biophysical models. When properly configured and evaluated, functional models provide probabilistic yield outlooks from their statistical component which can be used for risk assessment. The biophysical component of the functional models provides information on the key predictor variables from phenology-based processes such as the movement of water through the soilplant and atmospheric continuum. It also aids in the identification of limiting thresholds which will result in reduced yield when predictor variables assume less than their optimum values.

To forecast grain and oilseed crops across Canada, Agriculture and Agri-Food Canada (AAFC) developed a functional model: the Canadian Crop Yield Forecaster (CCYF) (Newlands et al. 2014). The CCYF provides in-season values of expected crop yield and production by seeded area at the end of the growing season starting with the first forecast in July. These forecasts are used as early warning information products by Statistics Canada, who report crop statistics at the national level, and the Market and Industry Services Branch at Agriculture and Agri-Food Canada, who monitor crop stocks for marketing purposes. Other users include the Strategic Policy and Program branches of Agriculture and Agri-Food Canada, who use crop forecasts to evaluate alternative policies and targeting of assistance to cropdeficit areas. Our objective in this study was to test the viability of using forecast data sets from the numerical weather prediction model at the Canadian Meteorological Centre (CMC) in forecasting canola and spring wheat yields on the Canadian Prairies. If significant statistical evidence can be established that the forecast data sets from the Global Ensemble Prediction System (GEPS) are superior to, or have the same predictive skill as the baseline data sets generated from climatology and near real-time observations, then these data sets can be used as an alternative source for making crop yield predictions from those Census Agricultural Regions (CARs) with poor station coverage. In the current setup of the CCYF, CARs without climate stations are assigned values from stations found in nearby CARs.

\section{MATERIALS AND METHODS}

\subsection{Brief description of the CCYF}

We first provide a brief overview of the CCYF. As described in Kouadio et al. (2014), the CCYF has 3 components: (1) preparing potential predictors from climate and the Normalized Difference Vegetation Index (NDVI), (2) automatic ranking of the 'best predictors' at the chosen unit of analysis (CAR in this study) and (3) sequentially forecasting crop yield in near real-time from observed and forecast data sets within-season to the end of the growing season. Preparing potential predictors is accomplished by generating the value-added climate variables such as the number of growing degree days (GDDs), crop water stress, accumulated precipitation and weekly composites of the NDVI. GDDs are calculated from the mean temperature above a base temperature of $5^{\circ} \mathrm{C}$ as:

$$
\mathrm{GDD}=\left(T_{\max }+T_{\min }\right) / 2-T_{\text {base }}
$$

where $T_{\max }$ is the daily maximum temperature, $T_{\min }$ is the daily minimum temperature and $T_{\text {base }}$ is the 
desired base temperature for accumulating heat units $\left(5^{\circ} \mathrm{C}\right.$ for cereals was used in this study) (Baier et al. 2000). Crop water stress (CWS) is calculated from the ratio of actual evapotranspiration to potential evapotranspiration using a form of the FAO56 method (Allen et al. 1998):

$$
\mathrm{CWS}=1-\mathrm{AET} / \mathrm{PET}
$$

where AET is actual evapotranspiration and PET is potential evapotranspiration. These variables are further aggregated at weekly, monthly and seasonal time steps.

Based on robust linear regression, the CCYF model is a linear combination of agroclimatic and NDVI predictors, as shown in Eq. 3:

$$
Y_{t}=\alpha_{0}+\alpha_{1} t+\sum_{k=1}^{\mathrm{n}} \beta_{i} X_{i_{t}}+\varepsilon_{t}
$$

where $Y_{t}$ is crop yield of year $t_{1} \alpha_{0}$ is the regression intercept, $\alpha_{1} t$ represents the technology trend of yield over time, $\beta$ is the slope of the regression coefficient, $x_{i, t}$ is the predictor $i$ in year $t$, and $i$ could be any of the predictors that are selected at run time-such as NDVI or agroclimatic indices - in any of the averaging periods; $t$ is the error term. Predictor variables for each run are automatically selected based on their contribution to the total variance, which cuts down on the number of predictor variables that could result in overfitting the model. A spatial correlation analysis is done at this point where CARs with similar leading predictor variables are grouped together. The multivariate regression model is then calibrated against all the data sets found in the region of similarity (Bornn \& Zidek 2012). The calibrated model against data sets from the grouped CARs becomes the predictive tool for that CAR. Having built the model at the CAR level, the statistical properties of predictors are generated from historical and withinseason data which are used to train the model to mimic climate and NDVI values for the remainder of the growing season using a stochastic approach (Dowd 2006). A random forest tree algorithm is used to generate as many outcomes of climate and NDVI values as possible (Breiman 2001, Biau 2012). With these outcomes, the final crop yields comprise a large sample which is represented as probability distribution of crop yield. Additional descriptions of CCYF methodology can be found in Newlands et al. (2014).

\subsection{Study area}

The evaluation of the CCFY with forecast data from the GEPS was conducted on the Canadian Prairies, which encompasses 3 provinces; namely Alberta, Saskatchewan and Manitoba (Fig. 1), and this accounts for $70 \%$ of the agricultural land of Canada (Statistics Canada 2016). In spite of the large agricultural extent, the Canadian Prairies receive the

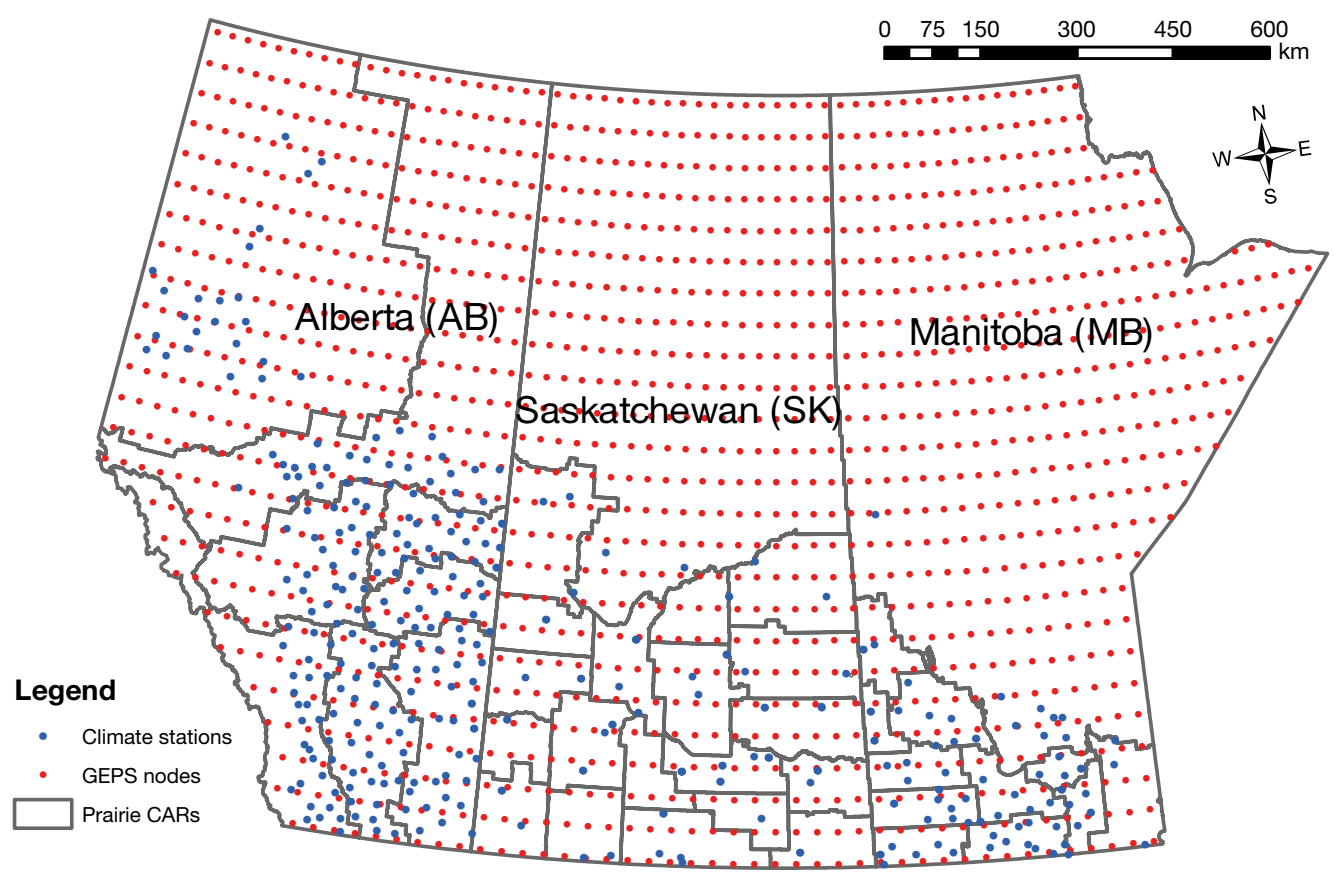

Fig. 1. Extent of the study area from the Canadian Prairie agricultural zone. Three provinces (Alberta, Saskatchewan and Manitoba) are included in this zone. Irregular polygons: Census Agricultural Regions (CARs); blue dots: climate stations found in the crop zone; red dots: $45 \mathrm{~km}$ nodes from the Global Environment Prediction System (GEPS) weather model 
least amount of precipitation (250-500 $\mathrm{mm}$ per growing season) compared to the rest of Canada, and the growing season (frost free season) is confined to a very narrow window of approximately 90-120 d (Phillips 1990). The soils are generally conducive to agriculture and consist of brown, dark brown and black chernosemic types moving from south to the northern fringes of the prairies (Shields et al. 1991). Spring wheat and canola were studied because of their respective economic significance to Canadian agriculture. Spring wheat is one of Canada's most extensive crops grown mainly for export, and has an annual average cash receipt of over Can $\$ 4$ billion (Statistics Canada 2016). Canola is one of Canada's most valuable crops, contributing about one-quarter of all farm receipts amounting to Can\$19.3 billion $\mathrm{yr}^{-1}$ to the Canadian economy (Canola Council of Canada 2013).

\subsection{Data requirements and processing}

The basic modelling unit in the CCYF is the CAR, which is the smallest unit at which observed or surveyed yield data from Statistics Canada are publicly available. CARs are represented by polygons of different sizes in the study area (Fig. 1). Other than for the administrative purposes of aggregating yields, CARs generally bear no resemblance to the distribution of biophysical factors such as soils and climate. To run the CCYF successfully, daily observed meteorological data consisting of maximum and minimum temperature and total precipitation are required from the start of the growing season to the prediction date. Beyond the prediction date to the end of the season, meteorological and the NDVI data sets are generated from a stochastic process. This involves updating the prior distribution of predictor variables with the near real-time data and selecting a random forest decision algorithm for multiple outcomes (Lobell et al. 2002). The stations which contributed meteorological data from the CARs are represented by dots from the study area (Fig. 1). Apart from meteorological data, the CCYF requires the NDVI as an input. The NDVI is calculated from optical sensors as the ratio of the difference between the infrared and the visible wave bands to their sum. NDVI comes from the Advanced Very High Resolution Radiometer (AVHRR) sensor on the EROS NOAA polar orbiting satellite and is distributed by the United States Geological Survey (USGS; https://lta.cr.usgs.gov/). The index is calculated as a composite and is aggregated every $7 \mathrm{~d}$ throughout the growing season. The generation of NDVI data beyond the forecast date was accomplished in a similar manner as the meteorological data. The NDVI data values were the same for baseline and GEPS simulation runs. The generation of forecast input data sets by statistical means is followed because there are usually no readily available skillful data sets from numerical prediction models that can be combined with the near real-time data sets during the growing season.

The forecast data from the CMC are on a regular grid and cover Canada from $48.6^{\circ}-60.3^{\circ} \mathrm{N}$ and $130.5^{\circ}-60.3^{\circ} \mathrm{W}$, with a horizontal resolution of $0.45 \times$ $0.45^{\circ}$ and a total number of $157 \times 27$ grid points (Fig. 1). For this study, only the nodes found in the Canadian Prairie region were used. The GEPS data were $32 \mathrm{~d}$ forecasts at a $45 \mathrm{~km}$ resolution and were comprised of 21 ensemble members. We tested the GEPS data from 1995-2012 and this data set had correlation skill levels of $\mathrm{R}=0.4-0.8$ for temperature and $\mathrm{R}=0.3-0.6$ for precipitation (Lin et al. 2016). Due to model drift in the medium to long-range prediction, GEPS forecast data were first corrected by subtracting the model bias which was estimated based on the available hind cast average. The 18 yr July model average (1995-2012) was subtracted from the yearly values in July. Different bias correction methods exist (Amengual al. 2012) but we chose the 'additive method' because of its simplicity. In our experimental setup, statistically generated predictor variables were replaced by the GEPS data during the July forecast. Our experiment was limited to July because July is when maximum leaf area index (LAI) is generally reached on the Canadian Prairies (Liu et al. 2010, Kross et al. 2015) and thus the upper limit of the potential yield is almost defined by July. To approximate the random forest generation of the multiple years of data in the baseline simulations, all of the available ensemble members from the GEPS generated data sets were used, from which an ensemble mean was calculated and compared with the median simulation from the baseline simulations.

\subsection{Analytical methods}

A leave-one-out cross-validation (LOOCV) scheme was implemented to generate hind cast evaluation statistics of crop yield from 1995-2012. The LOOCV uses all of the data to build the model except the test year, which is used for prediction. The evaluation was repeated iteratively until all years in the record were exhausted. The baseline simulations for the same period were subjected to the LOOCV analysis 
in the same manner as the GEPS simulations. The LOOCV technique is effective where the data record is short, as it allows the building of the model with all of the available data except for the test year. The CAR-level forecasts were further aggregated to provincial and regional levels using Statistics Canada's farm survey based reports of harvested area at the CAR level: www150.statcan.gc.ca/t1/tbl1/en/tv. action?pid $=3210000201$.

Three statistics were used to compare model outputs from the GEPS data and those from the baseline runs: the coefficient of determination (variance) $R^{2}$, the root mean square error (RMSE) and mean absolute percentage error (MAPE). $\mathrm{R}^{2}$ is the proportion of the variance in the dependent variable that is predictable from the independent variable(s). Being an expression of how well the predictor variables represent the outcome, it is usually expressed as the percent of data closest to the best line of fit, as in the following equation:

$$
\mathrm{R}^{2}=\left(\frac{\sum_{i=1}^{n}\left(O_{i}-\bar{O}\right)\left(P_{i}-\bar{P}\right)}{\sqrt{\sum_{i=1}^{n}\left(O_{i}-\bar{O}\right)^{2} \sum_{i=1}^{n}\left(P_{i}-\bar{P}\right)^{2}}}\right)^{2}
$$

where $O_{i}$ and $P_{i}$ are observed and predicted yield at forecast year $i$, and $n$ is the number of cases being tested.

The RMSE is the square root of the variance of the residuals. It indicates the absolute fit of the model to the data and shows how close the observed data points are to the model's predicted values. Lower values of RMSE indicate a better fit. RMSE is a good measure of how close the model predicts the outcome in comparison to observations, and is an important statistic where the main purpose of the model is prediction. It is calculated from:

$$
\operatorname{RMSE}=\sqrt{\sum_{i=1}^{n}\left(O_{i}-P_{i}\right)^{2} / n}
$$

where all the terms are as in Eq. (4).

MAPE is a measure of the prediction accuracy in the method used and takes into account the size of the error in percentage terms. If values of MAPE are low, they indicate better model performance. MAPE is therefore an indication of the skill or the quality of the forecast. It is calculated from:

$$
\mathrm{MAPE}=100 \frac{1}{n} \sum_{i=1}^{n}\left|\frac{O_{i}-P_{i}}{O_{i}}\right|
$$

where all the terms are as in Eq. (4). Because MAPE shows relative error as a percentage, it is a better index than the absolute error represented by the
RMSE in showing the temporal or spatial comparisons in model performance among different regions and crop types without the influence of the length of record. Finally, a statistical test was conducted with a Student's t-test (Zimmerman 1997), comparing yield forecast values of spring wheat and canola between the 2 data sets at 3 regional scales (CAR, Province and Prairie-wide).

\section{RESULTS}

Our goal was to assess whether the use of data outputs from the numerical weather prediction model (i.e. GEPS) supplied by CMC in making forecasts of canola and spring wheat yield improved the regional scale crop variability. We first compared the variance explained in canola and wheat prediction across the 3 Prairie Provinces (Fig. 2) from the GEPS and the baseline input data sets. The variance explained in observed yields were not very different between the 2 data sets and across the 2 crops; however, note that the variance explained was higher $(\sim 60 \%)$ in Alberta than Manitoba and Saskatchewan for canola. Between the 2 crops, the degree of agreement was closest for spring wheat (Fig. 2B) than canola (Fig. 2A). Overall, the variance explained with the GEPS data was higher than the baseline data by a few percentage points. When the variance explained was aggregated across the whole Prairie Region, the difference between the 2 data sets was minimal; however, there was approximately a $10 \%$ difference in the variance explained between Canola (just under $40 \%$ ) and spring wheat (just under $50 \%$ ). Knowing that the $\mathrm{R}^{2}$ statistic is an exploratory indicator of the relative goodness of fit without the advantage of providing causality by the predictor variables (Aldrich 1995), we examined other statistics, the RMSE and MAPE, which provide more information on the skillfulness and accuracy of the model predicted values compared to the observed values.

Results of the RMSE analysis were used as a proxy for identifying which experimental outcome between the 2 data sets provided a skillful forecast. If the RMSEs between the 2 data sets are not significantly different from zero, then no superiority in skill exits between the 2 and a very large difference in RMSE signifies low skill in predicting the observed outcomes between the 2 experiments. There was an indication that the GEPS meteorological data were slightly better in predicting canola yield in Alberta than in the other 2 provinces; however, the prediction of canola and spring wheat in the other 2 provinces 


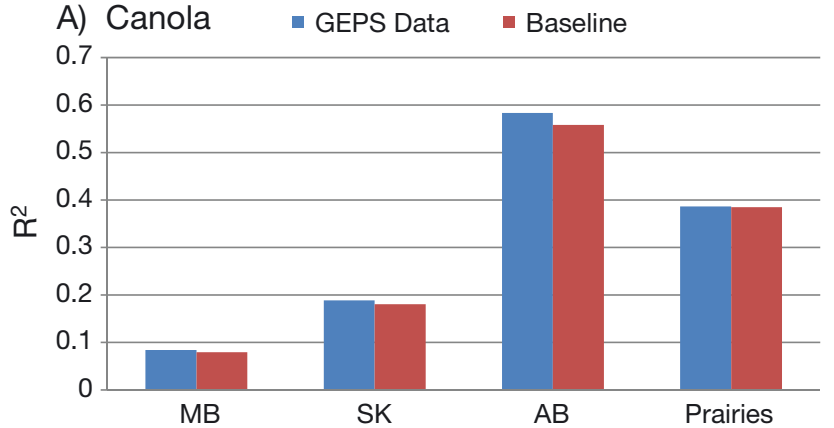

\section{B) Spring wheat}

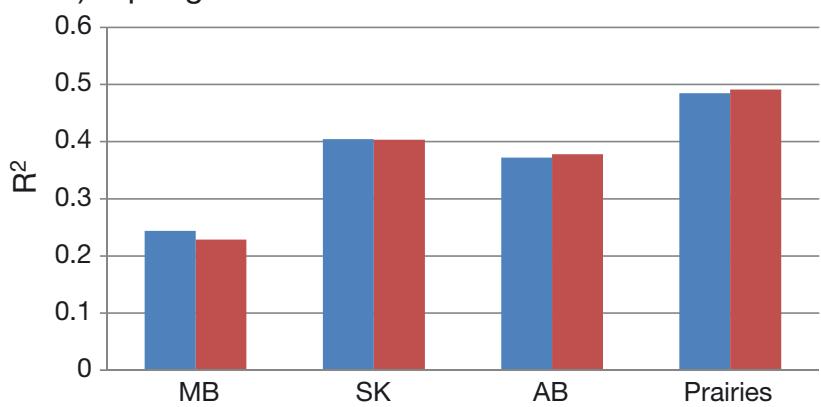

Fig. 2. Regional differences in the prediction of (A) canola and (B) spring wheat with the Global Environment Prediction System (GEPS) and the statistical (Markov-Chain Monte Carlo, MCMC) generated meteorological output data sets for the Canadian Prairie agricultural zone

was similar with RMSE values being about the same (Fig. 3). The aggregated RMSE across the 3 Prairie Provinces did not differ much between the 2 data sets, being under $250 \mathrm{~kg} \mathrm{ha}^{-1}$ for both canola and wheat.

To investigate further whether there was any spatial dependency in the skill arising from the type of meteorological data inputs used, the difference in RMSE between simulations obtained from the GEPS and baseline data outputs for canola and spring wheat was mapped across the agricultural landscape of the Prairie Provinces (Fig. 4). Differences in RMSE of around zero indicate no change in the explanatory power of the 2 input data sets; negative values show that the GEPS data were more skillful while positive RMSE values were an indication of better skill in the statistically generated meteorological data set. Spatially, the improvement in prediction skill was highest in central and southeastern Saskatchewan and the Peace River region from Alberta with respect to canola (Fig. 4A). Northern Saskatchewan remained unchanged. In addition, the majority of the agricultural regions from Alberta remained unchanged except for the north to south zone between the Alberta foothills and central Alberta, where the predictive skill diminished for canola when the GEPS data were used. The skill in the agricultural districts of southern

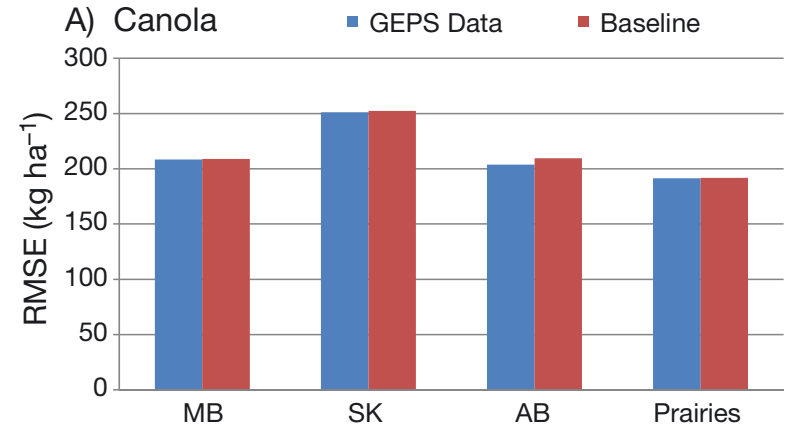

B) Spring wheat

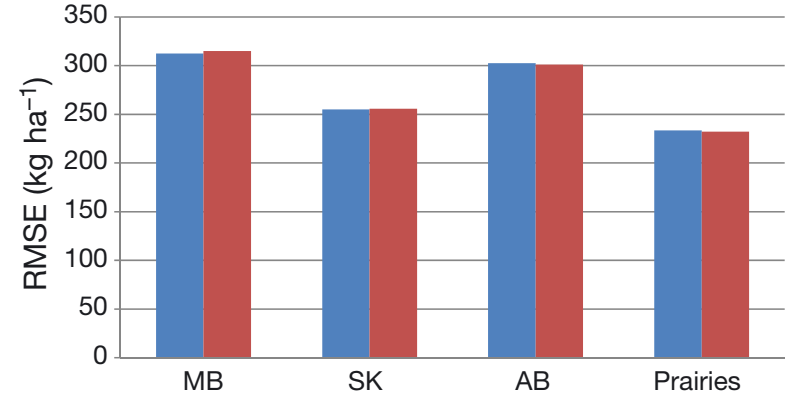

Fig. 3. Differences in the root mean squared error (RMSE) for (A) canola and (B) spring wheat when yield predictions were made with the Global Environment Prediction System and the statistical (MCMC) generated meteorological data outputs. The RMSEs for each data set were calculated with respect to the observed values and aggregated from the provincial to the Prairie Region

Manitoba remained unchanged while an improvement and degraded skill in the west central region were recorded for canola. With respect to spring wheat (Fig. 4B), the predictive skill in Alberta remained unchanged (east central) or degraded (west central and the Peace River region). The majority of the crop districts from central and southern Saskatchewan did not show any remarkable change when the GEPS data sets were used as inputs and in the case of 3 crop districts, the prediction skill improved, however 2 districts from the north recorded poor predictive skill. The change in the predictive skill in Manitoba for spring wheat was similar to Saskatchewan's, where crop districts with improved skill were sandwiched between districts with less (or no) predictive skill. The lack of a clear pattern or coherence in the spatial distribution of the predictive skill across the agricultural districts is probably indicative of the fact that apart from the meteorological variables, there were a multitude of other regional specific variables working in concert with the meteorological data. Deciphering what these variables are and understanding their interaction remains an interesting research question. The quality of the forecast as assessed from 


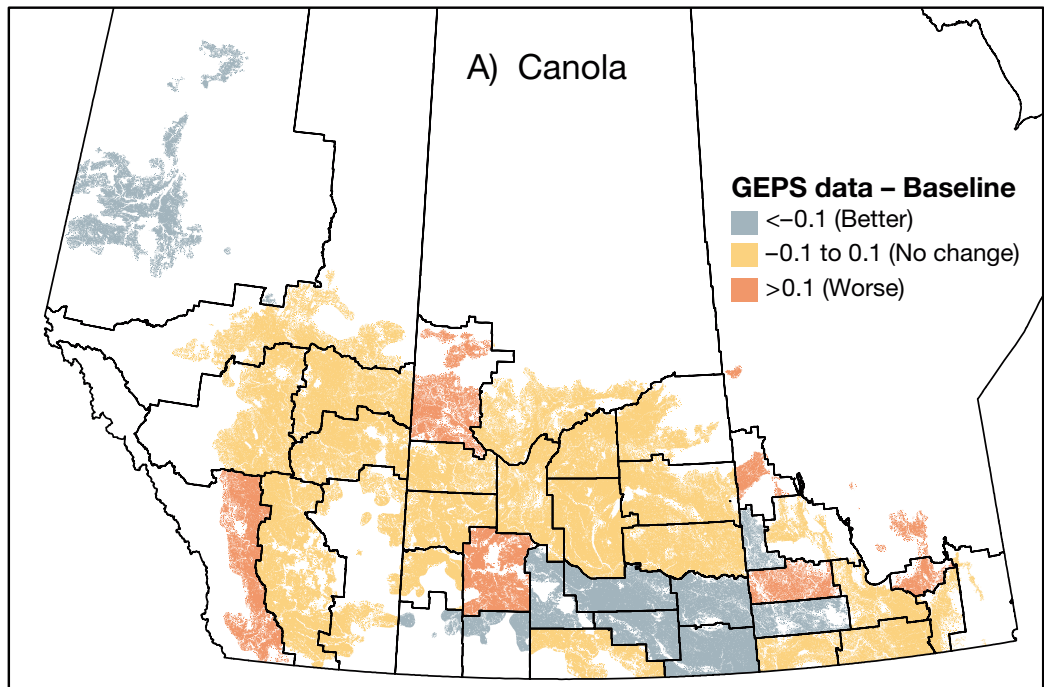

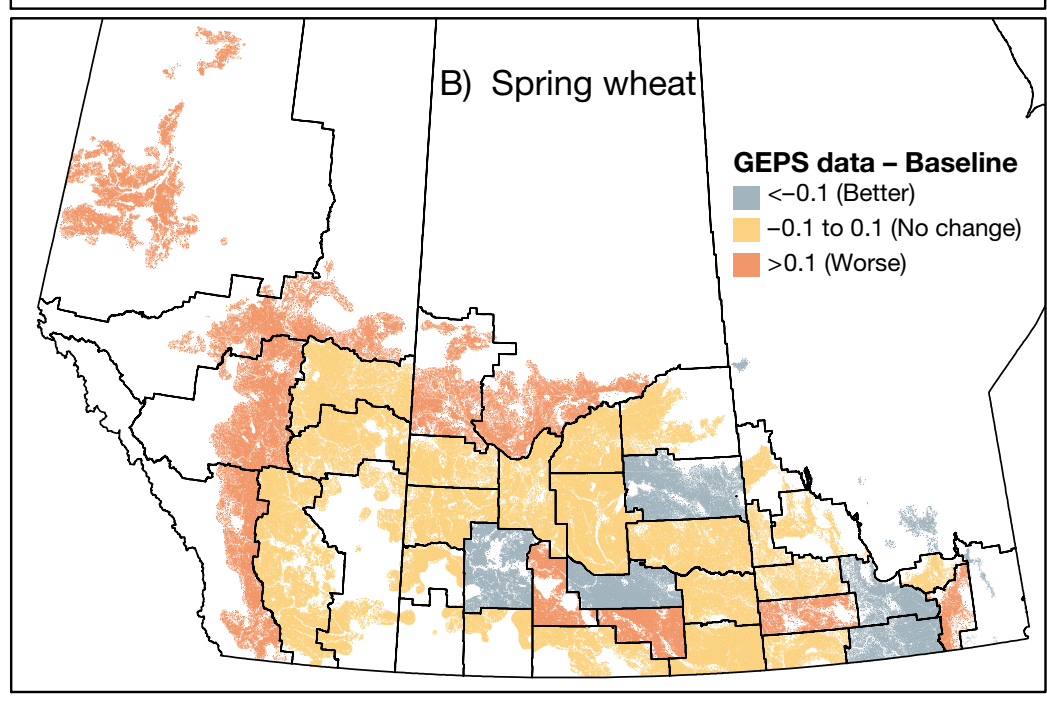

Fig. 4. Spatial comparison of the difference in root mean square error (RMSE) between simulations made with the Global Environment Prediction System (GEPS) and baseline data sets for (A) canola and (B) spring wheat. Agricultural areas with RMSE of around zero, below zero and above zero signify no change, improvement and reduction in predictive skill respectively between the 2 data sets

the MAPE statistic (Eq. 6) was used to compare relative errors between simulations from the 2 data sets. Like the forecast skill, we found improvements in the quality of the forecasts for canola from the agricultural districts of Alberta and Saskatchewan but no change from Manitoba (Fig. 5A). The aggregated forecast quality across the Prairie Region was a near tie of about $10 \%$ between the 2 data sets. There was no significant change in the quality of spring wheat forecasts across the 3 Prairie Provinces (Fig. 5B); however, there was a slight gain in Manitoba although this did not translate into an overall improvement cross the entire Prairie Provinces region.
Between spring wheat and canola, there was some improvement in the quality of forecasts when the GEPS data were used as inputs for the month of July (Fig. 6). Improvements were most noticeable in Saskatchewan and Manitoba but less so in Alberta for both canola and spring wheat. The exception in Alberta was in the Peace River Region, where the quality of forecasts improved for canola (Fig. 6A), and south-east central, where the quality of forecasts improved for spring wheat (Fig. 6B). As indicated in Fig. 5, the improvement in the quality of forecasts was not by a big margin (just under 2 percentage points over the baseline simulations), but recognizing that improvements came from those provinces where the density of the realtime climate stations is poor (Saskatchewan and Manitoba), this analysis suggests that the GEPS data sets can supplement the station observations and provide comparable skillful forecasts. This conclusion is supported by the fact that at both provincial and prairie-wide levels, there was no significant difference between yields as forecasted with the GEPS and baseline data sets (Table 1), although some differences were found at the CAR level.

\section{DISCUSSION}

In crop yield forecasting, the goal is to make a prediction with sufficient lead time so that users of the forecast can use this information to make decisions on management, transportation or any other decisions related to agricultural practice along the entire food chain. Typically, finding predictor variables that can capture the majority of the variance in the outcome as early as possible is challenging. In the CCYF tool, the major predictors are selected from a set of primary climate variables such as temperature and precipitation, with secondary variables (i.e. derived from primary variables) such as GDDs and crop water stress. In addition, other explanatory power comes from remote sensing derived predictors such as the weekly and monthly NDVI values for understanding 


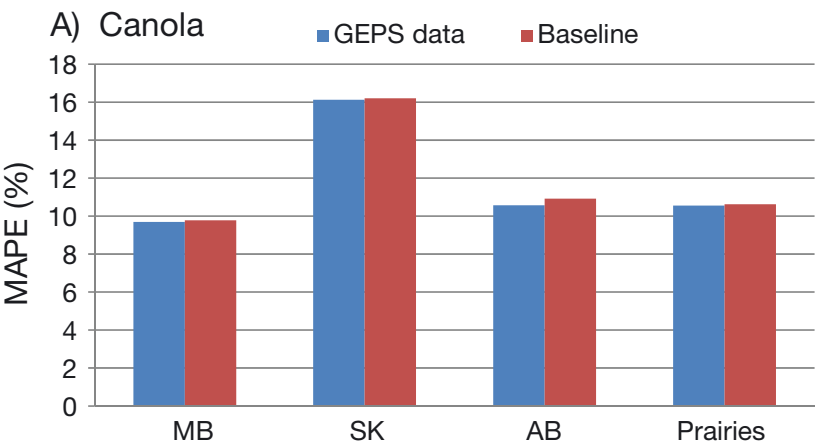

B) Spring wheat

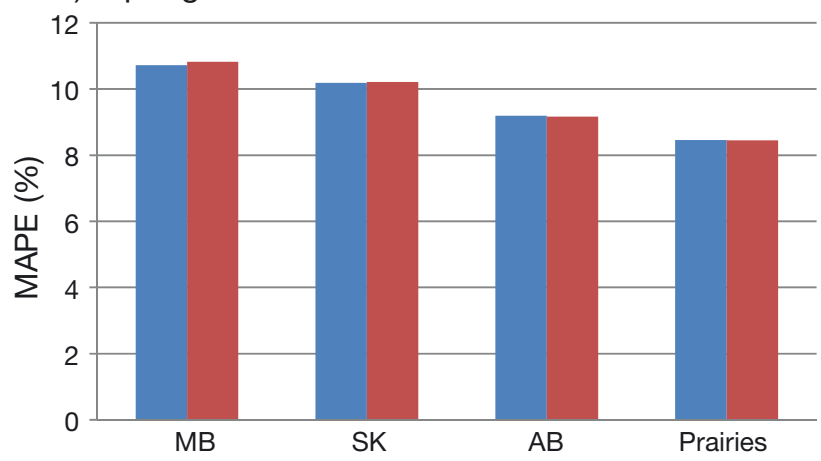

Fig. 5. Percentage differences in the mean absolute percentage error (MAPE) for (A) canola and (B) spring wheat when yield predictions were made with the Global Environment Prediction System (GEPS) and the statistical (MCMC) generated meteorological data sets

vegetation health and photosynthetic potential as determined by the LAI. Significant progress has been made in training predictive tools for future outcomes on historical and near real-time observations using machine learning algorithms to find more complex, nonlinear patterns in data for improved model prediction (Hsieh et al. 1999, Jean et al. 2016). In our prediction of canola and spring wheat across the Canadian Prairies, we built prediction data sets using machine learning instructions to establish a 'baseline' for forecasting canola and spring wheat. The reason for searching for alternative data sets came from a realization that the success of training a yield prediction tool, such as the CCYF, depends on the availability of granular observations temporally and spatially; however, agricultural districts on the Canadian Prairies do not always have the minimum density of observation points for which to train the crop prediction model. The numerical weather prediction data outputs at the $32 \mathrm{~d}$ outlook provided an alternative data set to test the early prediction of canola and spring wheat yields with the CCYF.

Our results show that the numerical weather prediction outputs of precipitation and temperature, when combined with the near real-time observations at 1 mo before the end of the growing season, attained overall forecast accuracies which were comparable to the baseline prediction. Both the baseline and GEPS data sets compared the final prediction to actual observation at the end of the season and there was little difference between the 2 data sets; however, $\mathrm{R}^{2}$ was higher for canola than spring wheat in some CARs when the GEPS data were used. Likewise, the RMSE values were relatively smaller for canola when the GEPS data were used but remained almost the same for spring wheat. The aggregated variance explained across the Prairies for canola was relatively higher for the GEPS data than the baseline and reached a maximum of 0.58 in Alberta. For spring wheat, the variance explained for both data sets was relatively the same between the 2 data sets except in Manitoba where the GEPS variance was relatively higher. Although the gain in skill was not significantly different for using the GEPS data set, this data set maintained the timeliness of providing a yield forecast in July, which is 1 or 2 mo before harvest. An opportunity therefore exists to use the GEPS data as alternative input into the CCYF where climate stations are sparse or the climate record is short. Generating input climate data sets from probability functions for an area works better if the density of stations is high and there is a long history of data collection. Many agricultural districts, especially those from central Saskatchewan and some southern districts from Manitoba, do not have a high enough density of stations from which to build and train the CCYF model. In a previous study, for example, it was found that some crop districts relied on climate stations from neighbouring crop districts (Kouadio et al. 2014). Because the GEPS data sets are generated from a numerical weather prediction model using a fixed day and time, there is an assured availability of data during simulation runs, and all locations in the study area are provided with data at a fine resolution of $45 \mathrm{~km}$. In southern Saskatchewan, for example, some crop districts had only 1 or 2 climate stations for generating the baseline climate predictors but there were at least 4 to 5 nodes from the GEPS data sets for generating the climate data inputs. These nodes were evenly distributed across the agricultural districts, unlike the baseline data which had a skewed distribution, favouring the settled southern districts of the study area.

Although there was a relative improvement in the predictive skill of canola over spring wheat with the GEPS data, we were unable to pinpoint the exact source of this gain. Generally, the majority of canola varieties grown on the Canadian Prairies are sensitive to higher than optimum temperatures (the pre- 

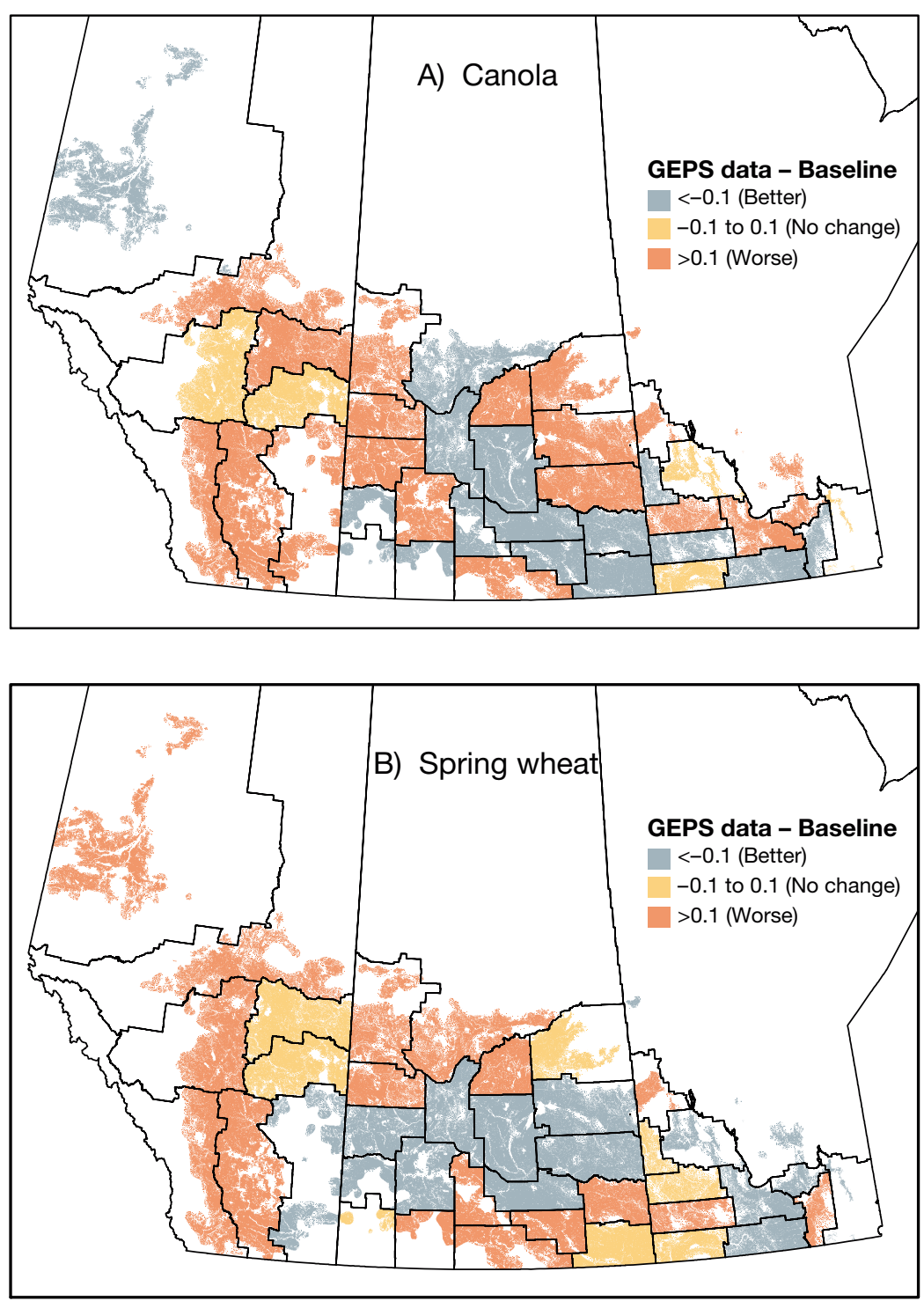

Fig. 6. Spatial comparison of the difference in mean absolute percentage error (MAPE) between simulations made with the Global Environment Prediction System (GEPS) and baseline data sets for (A) canola and (B) spring wheat. Values shown are the difference in MAPE between the GEPS and baseline data sets ferred conditions being associated with cool conditions) and can withstand a wide range of moisture conditions; however, water stress during the reproductive phase in canola is associated with floral abortion and fertilization failure while the translocation of sugars to grains is reduced in wheat if water stress is excessive (Fischer 1973). Our study covered an $18 \mathrm{yr}$ period (1995-2012), which is generally considered as a pluvial phase in relation to the historical droughts of the Canadian Prairies (Sauchyn \& Ilich 2017). The wet phase, however, did not preclude the occurrence of drought events which, according to Stewart el al. (2011), were sometimes juxtaposed with within the same year. The 18 yr study period was not characterised by exceptionally hotter than usual summer temperatures (see temperature trends from Environment Canada and Climate Change at www.currentresults.com/WeatherExtremes/Canada/trends-temperatureseasonal.php). The observed rise in temperature across the study region under climate change studies is usually ascribed to the rise in the minimum temperature during the winter, spring and autumn months. In all likelihood, therefore, the climatic conditions for the study period favoured canola yield and production. Yield performance, however, is also affected by other factors including management and economic considerations. These were not taken into account in this study.

Table 1. Statistical significance test of the differences between yields forecasted from Global Environment Prediction System (GEPS) and by baseline climate data sets for spring wheat and canola at 3 regional scales (2-sample $t$-test assuming equal variances). CAR: Census of Agricultural Regions

\begin{tabular}{|c|c|c|c|c|c|c|}
\hline \multirow[b]{2}{*}{ Crop } & \multicolumn{2}{|c|}{ CAR } & \multicolumn{2}{|c|}{ _ Province } & \multicolumn{2}{|c|}{ Prairies } \\
\hline & Spring wheat & Canola & Spring wheat & Canola & Spring wheat & Canola \\
\hline GEPS mean & 36.0 & 28.3 & 37.9 & 29.4 & 36.8 & 28.8 \\
\hline Baseline mean & 35.4 & 27.5 & 37.1 & 28.7 & 35.9 & 28.2 \\
\hline Pooled variance & 60.0 & 21.8 & 26.6 & 10.9 & 10.1 & 6.4 \\
\hline Sample size & 720 & 720 & 54 & 54 & 18 & 18 \\
\hline p-value (2-tailed) & 0.094 & 0.003 & 0.42 & 0.32 & 0.38 & 0.48 \\
\hline Conclusion & $\begin{array}{l}\text { Difference is } \\
\text { significant at } \\
\text { the } 90 \% \text { con- } \\
\text { fidence level }\end{array}$ & $\begin{array}{l}\text { Difference is } \\
\text { significant at } \\
\text { the } 99 \% \text { con- } \\
\text { fidence level }\end{array}$ & $\begin{array}{c}\text { Difference is } \\
\text { not } \\
\text { significant }\end{array}$ & $\begin{array}{c}\text { Difference is } \\
\text { not } \\
\text { significant }\end{array}$ & $\begin{array}{c}\text { Difference is } \\
\text { not } \\
\text { significant }\end{array}$ & $\begin{array}{c}\text { Difference is } \\
\text { not } \\
\text { significant }\end{array}$ \\
\hline
\end{tabular}


In a previous study by Chipanshi et al. (2015), it was shown that predictor variables in the CCYF are selected on the basis that they contribute a significant amount of variance to the projected yield. However, due to the statistical nature of the CCYF, some variables which may not have any biophysical meaning are sometimes selected. For example, the NDVI may be selected as a predictor after July when its significance is diminished since the maximum leaf area is past. We are conducting an analysis of predictor selection at the sub-CAR level, which will likely lead to improved selection of predictor variables to which physical meaning can be attached.

\subsection{Summary of findings}

We tested an alternative data set (the 32 d numerically generated meteorological values of temperature and precipitation from the GEPS) to predict canola and spring wheat on the Canadian Prairies during the growing season. We demonstrated that the GEPS data set has similar prediction skill as the statistically generated values of temperature and precipitation for spring wheat and showed improved prediction skill for canola over the baseline data sets. In the Canadian Prairie environment where climatic records are short and spatially insufficient, the GEPS data set can be used as a supplement or alternative data source. The design of our experiment was intended to replicate the operational setup of the CCYF where the real-time data sets from the start of the growing season are joined with the statistically generated unknown values for the rest of the growing season. The longest timeframe into the future for the current GEPS data outputs is $32 \mathrm{~d}$. As much as these data sets were available in hind cast format, they could not be used on their own for the entire growing season because of their non-availability beyond $32 \mathrm{~d}$ in real time. New data sets from other prediction systems with a longer time frame, such as the Canadian Seasonal to Inter-annual Prediction Systems (CanSIPS) (Merryfield et al. 2013), will likely address this gap.

\subsection{Priorities for future research}

The skillfulness of a crop forecast depends on the quality of the input data sets used. As more and more skillful numerical climate data sets become available at finer resolution, it will be possible to generate skillful crop yield forecasts at longer lead times, such as a season. The normalized vegetation indices, however, are difficult to project ahead of the growing season. In addition, the within-season NDVI values are prone to cloud and haze conditions, hence the use of composite weekly values. Radar satellites, unaffected by these conditions, provide better data continuity and mean data are becoming available every 2-3 d and at high resolutions (10-50 m). Integrating these data sources in crop yield forecasting will bring significant improvement to the spatial and temporal simulation of crop yields. Attaching physical meaning to predictor variables in the CCYF will further improve our understanding of crop and environmental interactions.

Acknowledgements. This work was supported by A-base funds provided under the Science and Technology Branch of Agriculture and Agri-Food Canada (AAFC), Growing Forward 2 Agriculture Policy framework (Project J-001045).

\section{LITERATURE CITED}

Aldrich J (1995) Correlations genuine and spurious in Pearson and Yule. Stat Sci 10:364-376

Allen RG, Pereira LS, Raes D, Smith M (1998) FAO PenmanMonteith equation. In: Crop evapotranspiration-Guidelines for computing crop water requirements-FAO Irrigation and drainage paper 56. Food and Agricultural Organization of the United Nations, Rome, p 2-15

Amengual A, Homar V, Romero R, Alonso S, Ramis C (2012) A statistical adjustment of regional climate model outputs to local scales: application to Platja de Palma, Spain. J Clim 25:939-957

Baier W, Boisvert JB, Dyer JA (2000) The versatile soil moisture budget reference manual. Agriculture and AgriFood Canada, Ottawa, p A1-D4

Biau G (2012) Analysis of a random forests model. J Mach Learn Res 13:1063-1095

*Bornn L, Zidek JV (2012) Efficient stabilization of crop yield prediction in the Canadian Prairies. Agric For Meteorol 152:223-232

* Breiman L (2001) Random forests. Mach Learn 45:5-32

Canola Council of Canada (2013) Economic impact of the canola industry. www.canolacouncil.org/markets-stats/ industry-overview/economic-impact-of-the-canola-industry/

Chipanshi A, Zhang Y, Kouadio L, Newlands N and others (2015) Evaluation of the Integrated Canadian Crop Yield Forecaster (ICCYF) model for in-season prediction of crop yield across the Canadian agricultural landscape. Agric For Meteorol 26:137-150

Wowd MA (2006) A sequential Monte Carlo approach for marine ecological prediction. Environmetrics 17:435-455

FAO (2014) Global Information and Early Warning System (GIEWS) on food and agriculture. Trade and Markets Division, FAO, Rome. www.fao.org/Giews/english/index. htm

Fischer RA (1973) The effect of water stress at various stages of development on yield processes in wheat. In: Slayter RO (ed) Plant response to climatic factors. Proc UNESCO, Uppsala Symposium 1970. UNESCO, Paris, p 233-241 
Hoogenboom G, Porter CH, Shelia V, Boote KJ and others (2017) Decision Support System for Agrotechnology Transfer (DSSAT) version 4.7. DSSAT Foundation, Gainesville, FL. https://DSSAT.net

Hsieh WW, Tang B, Garnett ER (1999) Teleconnections between Pacific sea surface temperatures and Canadian Prairie wheat yield. Agric Meteorol 96:209-217

Jame YM, Cutforth HW (1996) Crop growth models for decision support systems. Can J Plant Sci 76:9-19

Jean N, Burke M, Xie M, Davis WM, Lobell DB, Ermon S (2016) Combining satellite imagery and machine learning to predict poverty. Science 353:790-794

Johnson DM (2014) An assessment of pre- and withinseason remotely sensed variables for forecasting corn and soybean yields in the United States. Remote Sens Environ 141:116-128

Kouadio L, Newlands KN, Davidson A, Zhang Y, Chipanshi A (2014) Assessing the Performance of MODIS NDVI and EVI for seasonal crop yield forecasting at the ecodistrict scale. Remote Sens 6:10193-10214

Kross A, McNairn H, Lapen D, Sunohara M, Champagne C (2015) Assessment of RapidEye vegetation indices for estimation of leaf area index and biomass in corn and soybean crops. Int J Appl Earth Obs Geoinf 34:235-248

Lin H, Gagnon N, Beauregard S, Muncaster R, Markovic M, Denis B, Charron M (2016) GEPS-based monthly prediction at the Canadian Meteorological Centre. Mon Weather Rev 144:4867-4883

Liu J, Pattey E, Miller JR, McNairn H, Smith A, Hu B (2010) Mapping variability of above-ground dry biomass and yield of corn using multi-temporal hyperspectral and multispectral remote sensing data. Remote Sens Environ 114:1167-1177

Lobell DB, Hicke JA, Asner GP, Field CB, Tucker CJ, Los SO (2002) Satellite estimates of productivity and light use efficiency in United States agriculture, 1982-98. Glob Change Biol 8:722-735

Merryfield WJ, Lee WS, Boer GJ, Kharin VV and others (2013) The Canadian seasonal to interannual prediction system. I. Models and initialization. Mon Weather Rev 141:2910-2945

Newlands N, Zamar D, Kouadio AL, Zhang Y and others (2014) An integrated, probabilistic model for improved seasonal forecasting of agricultural crop yield under environmental uncertainty. Front Environ Sci 2:17

Nikolova S, Bruce S, Randall L, Barrett G, Ritman K, Nicholson $M(2012)$ Using remote sensing data and crop modelling to improve crop production forecasting: a scoping study. Technical Report 12.3. Australian Bureau of Agricultural and Resource Economics and Sciences (ABARES), Canberra

Editorial responsibility: Gerrit Hoogenboom, Gainesville, Florida, USA
Phillips D (1990) The climates of Canada. Environment Canada, Downsview

*Qian B, De Jong R, Warren R, Chipanshi A, Hill H (2009) Statistical spring wheat yield forecasting for the Canadian Prairie Provinces. Agric For Meteorol 149:1022-1031

Reichert GC, Caissy D (2002) A reliable crop condition assessment program (CCAP) incorporating NOAA AVHRR data, a geographical information system, and the internet. In: Proc Environmental Systems Research Institute (ESRI) User Conf, 8-12 July 2002, San Diego, CA. http://geodepot.statcan.gc.ca/ccap-peec/esri2002 conf-eng.jsp

Sauchyn D, Ilich N (2017) Nine hundred years of weekly streamflows: stochastic downscaling of ensemble treering reconstructions. Water Resour Res 53:9266-9283

Shields JA, Tarnocai C, Valentine KWG, Macdonald K B (1991) Soil landscapes of Canada: procedures manual and user handbook. LRRC contribution number 88-29. Land Resource Research Centre, Research Branch, Agriculture Canada, Ottawa

Statistics Canada (2016) Farm cash receipts. www.statcan. gc.ca/tables-tableaux/sum-som/101/cst01/agri03a-eng. $\mathrm{htm}$

Stephens DJ, Walker GK, Llyons TJ (1994) Forecasting Australian wheat yields with a weighted rainfall index. Agric For Meterol 71:247-263

Stewart RE, Henson W, Carmichael H, Hanesiak J, Szeto K (2011) Precipitation events during the recent drought. In: Stewart R, Lawford R (eds) The 1999-2005 Canadian Prairie drought: science, impacts and lessons. Drought Research Initiative, Winnipeg, p 43-46

USAID (US Agency for International Development) (2014) Famine early warning system network (FEWS NET). United States Agency for International Development (USAID), Washington, DC. www.fews.net

van Diepen K, Boogaard H, Supit I, Lazar C, Orlandi S, Van der Goot E, Schapendonk A (2004) Methodology of the MARS crop yield forecasting system. In: Lazar C, Genovese G (eds) Agrometeorological modelling, processing and analysis. EUR 21291 EN/2, Methodology of the MARS crop yield forecasting system, Vol 2: agrometeorological data collection processing and analysis. European Commission, Luxembourg

Walker GK (1989) Model for operational forecasting of western Canada wheat yield. Agric For Meteorol 44: 339-351

Wu B, Meng J, Li Q, Yan N, Du X, Zhang M (2014) Remote sensing-based global crop monitoring: experiences with China's Crop Watch system. Int J Digit Earth 7:113-137

K Zimmerman DW (1997) A note on interpretation of the paired-samples $t$ test. J Educ Behav Stat 22:349-360

Submitted: April 9, 2018; Accepted: November 20, 2018

Proofs received from author(s): January 21, 2019 